\title{
Desafios da enfermagem no processo de doação para transplante de órgãos: revisão integrativa
}

Nursing challenges in the soft organ transplant donation: integrative review

Desafíos de la enfermería en el proceso de donación de trasplante de órganos: revisión integradora

Julia Barbosa de Magalhães ${ }^{1}$, Renata da Silva Schulz ${ }^{1 *}$, Tyciana Paolilo Borges ${ }^{1}$, Rosinete Souza Barata ${ }^{1}$, Kelly Cruz Pimentel Sampaio ${ }^{1}$, Rosangela Rodrigues Lima ${ }^{1}$, Darci de Oliveira Santa Rosa ${ }^{1}$.

\section{RESUMO}

Objetivo: Identificar os desafios enfrentados pela enfermagem no processo de doação para transplantes de órgãos. Métodos: Revisão integrativa, realizada nas bases de dados Medical Literature Analysis and Retrieval System Online (MEDLINE), Scientific Eletronic Libray Online (SciELO), Biblioteca Virtual em Saúde (BVS) e Literatura Latino-americana e Caribe em Ciências da Saúde (LILACS), no período de 2014 a 2019. Os descritores associados foram: Obtenção de Tecidos e Órgãos, Transplante e Enfermagem Resultados: A amostra foi composta por 9 artigos que apresentam a necessidade de promover educação continuada no processo de captação e revelam dificuldades nas estratégias de saúde para disseminar informações sobre a importância do ato da doação e promoção da sensibilização. Os desafios enfrentados pela equipe de enfermagem afetam o planejamento e as estratégias para o estímulo ao ato de doar, o que impacta nas dificuldades frente ao processo de doação e captação de órgão para transplante. Considerações finais: Os principais desafios encontrados pela enfermagem durante o processo de doação foram: dificuldades na identificação e confirmação da morte encefálica e a negação/recusa familiar. E como soluções aos desafios estão: priorizar as comissões intra-hospitalares, as avaliações clínicas e a comunicação adequada da equipe com a família.

Palavras-chave: Obtenção de tecidos e órgãos, Transplante, Enfermagem.

\begin{abstract}
Objective: To identify the challenges faced by nursing in the process of organ transplant donation. Methods: Integrative review conducted in the following databases: Medical Literature Analysis and Retrieval System (MEDLINE), Scientific Electronic Library Online (SciELO), Virtual Health Library (VHL) and Latin American and Caribbean Health Sciences Literature (LILACS) from 2014 to 2019. The descriptors associated were: Tissue and Organ Procurement, Transplant and Nursing. Results: The sample consisted of 9 articles that show the need to promote continuing education in the recruitment process and reveal difficulties in health strategies to disseminate information about the importance of the act of donation and promotion of awareness. The challenges faced by the nursing team affect the planning and strategies for stimulating the act of donating, which impacts the difficulties in the process of donating and obtaining an organ for transplantation. Final considerations: The main challenges encountered by nursing during the donation process were: difficulties in the identification and confirmation of brain death and family denial / refusal. And how solutions to the challenges are: prioritizing intra-hospital commissions, clinical assessments and adequate communication between the team and the family.
\end{abstract}

Key words: Tissue and organ procurement, Transplant, Nursing.

1Universidade Federal da Bahia (UFBA), Salvador - BA. *E-mail: renata.s.schulz@gmail.com 


\section{RESUMEN}

Objetivo: Identificar los desafíos que enfrenta la enfermería em el proceso de donación para trasplantes de órganos. Métodos: Revisión integradora em las bases de datos Medical Literature Analysis and Retrieval System Online (MEDLINE) Scientific Eletronic Libray Online (SciELO), Biblioteca Virtual de Salud (BVS) e Literatura Latinoamericana y Caribeña en Ciencias de la Salud (LILACS) de 2014 a 2019. Los descriptores associados fueron: Obtención de Tejidos y Órganos,Trasplante y Enfermería. Resultados: La muestra consistió em 9 artículos presentan la necesidad de promover la educación continua en el proceso de donación de organos y revelan dificultades en las estrategias de salud para difundir información sobre la importancia del acto de donación y la promoción de la conciencia. Los desafíos que enfrenta el equipo de enfermería afectan la organización y las estrategias para estimular el acto de donar, lo que afecta las dificultades en el proceso de donación y las tasas de donación. Consideraciones finales: Los principales desafíos encontrados por la enfermería durante el proceso de donación se encuentran: dificultades para identificar y confirmar la muerte cerebral y la negación / sin permisso familiar. Resolver los desafíos implica: priorizar las comisiones intrahospitalarias, las evaluaciones clínicas y la comunicación adecuada entre el equipo y la familia.

Palabras clave: Obtención de tejidos y órganos, Trasplante, Enfermería.

\section{INTRODUÇÃO}

Autorizar a remoção de um órgão com o propósito de doação para transplante se constitui em uma atitude solidária e, por isso, essa doação deve sempre ser feita de forma gratuita (BRASIL, 2017). O resultado de uma doação pode significar salvar vidas ou mesmo possibilitar, para aquele que recebe, manutenção de uma vida com qualidade. Existem situações clínicas graves, nas quais o transplante de órgãos é a única opção para a sobrevida das pessoas que apresentam declínio corporal desencadeado pela função de um órgão. É uma terapia necessária quando outras terapias já não conseguem mais gerar bons resultados, o que torna esse processo de grande relevância social e pública (WESTPHAL GA, et al., 2011).

O transplante de órgãos é, simultaneamente, um procedimento cirúrgico e terapêutico. É um procedimento cirúrgico, pois envolve a retirada de órgão ou tecido sadios de um doador, vivo ou falecido, e a transferência para outra pessoa (receptor), ou para a mesma pessoa, no caso de tecido (autotransplante). Outrossim, é procedimento terapêutico, pois com essa transferência pode resultar em compensação ou reconstituição de uma função prejudicada ou substituição de uma função perdida (BRASIL, 2020).

No território brasileiro, a retirada de órgãos para fins de transplante é regulada pela Lei no 9.434/97, que por sua vez, é regulamentada pelo Decreto no 9.175, de 18 de outubro de 2017 (BRASIL, 1997; BRASIL, 2017). Em 2001, a Lei no 11.211/2001 alterou dispositivos da Lei no 9.434/97, para determinar a existência da doação consentida. Assim, a remoção de órgãos de doador falecido dependerá da autorização de cônjuge ou parente, maior de idade, observando-se a linha sucessória, reta ou colateral, até o segundo grau (BRASIL, 2001).

Para o Conselho Federal de Medicina (CFM), doador falecido é aquele que sofre morte encefálica (ME), isto é, pessoa com parada total e irreversível de todas as funções do cérebro que foi constatada e cuja causa dessa parada é conhecida (BRASIL, 2017). O paciente em ME é visto como potencial doador. Assim, ao identificar um paciente nessa condição a notificação de ME é compulsória e dirigida à Central de Notificação, Captação e Distribuição de Órgãos e Tecidos (CNCDO), descentralizada em Organização de Procura de Órgãos (OPOs).

A notificação de um potencial doador à CNCDO do respectivo estado deve ser realizada pelo médico ou enfermeira da unidade hospitalar e essa notificação deve ser entendida como compromisso ético desses profissionais. As OPOs e as Comissões Intra-Hospitalares de Doações de Órgãos e Tecidos para Transplante (CIHDOTTs) são redes de descentralização e articulação para a identificação de potenciais doadores (MATTIA AL, et al., 2010).

REAS/EJCH | Vol.12(10) | e4195 | DOI: https://doi.org/10.25248/reas.e4195.2020 Página 2 de 10 
Na doação de órgãos e tecidos para transplantes temos sentimentos opostos vivenciados pelas pessoas envolvidas no processo, de um lado a tristeza pela morte de ente querido, do outro a felicidade do receptor pela oportunidade de uma nova perspectiva de vida com mais qualidade. Para atuar com segurança nesta situação de dicotomia a equipe de saúde necessita estar atualizada com a definição de ME, sua identificação, condutas e manutenção ao potencial doador são fundamentais ao processo de uma doação efetiva (FREIRE ILS, et al., 2012).

O processo de doação de órgão para transplante é complexo e envolve uma série de etapas: identificação do potencial doador, notificação, avaliação, informação do doador efetivo, seleção dos receptores, identificação das equipes transplantadoras, retirada dos órgãos, liberação do corpo (MATTIA AL, et al., 2010). Neste contexto, a atuação da enfermeira ganha destaque, pois sua participação nesse processo é imprescindível para a viabilização e sucesso do procedimento (MORAES EL, et al., 2014).

Dessa forma, a Resolução Cofen 611, de 2019, entendendo ser a doação de órgão um processo complexo, determinou que cabe à enfermeira planejar, executar, coordenar, supervisionar e avaliar os procedimentos de enfermagem realizados com os doadores de órgãos e tecidos. Na maioria das vezes é a enfermeira que entrevista a família ou responsáveis legais, no caso do potencial doador com diagnóstico de ME, para identificar se eles compreenderam esse diagnóstico e o interesse deles na doação dos órgãos do familiar falecido para o transplante em outra pessoa (BRASIL, 2019).

Entretanto, apesar da relevante função da enfermeira no processo de doação e transplante de órgãos e tecidos, há diversos desafios vivenciados pela equipe até que todo processo seja efetivado. Entre estes desafios pode-se citar a subnotificação de ME, no Brasil para cada 8 potenciais doadores, somente um deles é identificado (ABTO, 2020). Conforme o Registro Brasileiro de Transplante (RBT) em 2019 quase 40.000 pessoas, no território brasileiro, aguardavam na Lista de Espera para transplante de órgão ou tecido, neste mesmo ano a recusa familiar foi de $40 \%$.

Desta forma, a participação dos profissionais de enfermagem na doação de órgãos, pode contribuir para a sobrevida dos pacientes que esperam na fila do transplante (DALBEM GG e CAREGNATO RCA, 2010). Neste contexto, a atuação da enfermagem, no processo de doação de órgãos, está atrelada a conscientização do familiar para a autorização do procedimento e a manutenção do potencial doador. Outra função fundamental é manter o equilíbrio do organismo para garantir a qualidade do órgão para o transplante e efetivação da doação. Assim, este estudo tem como objetivo: Identificar, na literatura, os desafios enfrentados pela enfermagem no processo de doação para transplante de órgãos.

\section{MÉTODOS}

Trata-se de uma revisão integrativa, sobre evidências na literatura, a respeito dos desafios enfrentados pela enfermagem no processo de doação para transplante de órgãos. Segundo Mendes KDS, et al. (2008) este método de pesquisa segue seis etapas indicadas, as quais são: 1) identificação do tema e seleção da hipótese ou questão de pesquisa para a elaboração da revisão integrativa; 2) estabelecimento de critérios para inclusão e exclusão de estudos/ amostragem ou busca na literatura; 3) definição das informações a serem extraídas dos estudos selecionados/ categorização dos estudos; 4) avaliação dos estudos incluídos na revisão integrativa; 5) interpretação dos resultados; e 6) apresentação da revisão/síntese do conhecimento. Assim, esse método permite a condensação dos estudos já publicados na temática escolhida.

Para alcance do objetivo desse estudo foi elaborada a questão norteadora: Como se apresentam na literatura os desafios enfrentados pela enfermagem no processo de doação para transplante de órgãos? Foram utilizadas as bases de dados bibliográficas MedLine/PubMed, LILACS, SciELO e BVS. As buscas se limitaram aos artigos publicados nos últimos 5 anos e o período de coleta dos artigos ocorreu entre março de 2018 a janeiro de 2019.

A seleção dos estudos foi realizada por meio dos seguintes descritores: "Obtenção de Tecidos e Órgãos", "Transplante", "Enfermagem" de acordo com os Descritores em Ciência da Saúde (DeCS) e Medical Subject Headings (MeSH) que foram associados ao booleano "AND". 
Os critérios de inclusão foram: artigos originais completos disponíveis na íntegra nos idiomas português, inglês e espanhol. Foram excluídos os trabalhos duplicados, as revisões de literatura, os textos de atualização, os editoriais, as cartas ao leitor, os relatos de experiências, dissertações e teses.

A princípio foi realizada a leitura dos títulos e resumos encontrados, e em seguida, foi realizada leitura mais aprofundada do material pré-selecionado na busca de informações pertinentes para a discussão da temática proposta.

\section{RESULTADOS}

O levantamento de artigos a respeito dos desafios enfrentados pela enfermagem no processo de doação para transplante de órgãos, inicialmente, resultou em 865 artigos. Seguindo a leitura de título e resumo foram selecionados 54 estudos. Por fim, após a leitura na íntegra para analisar se contemplavam o objeto do presente trabalho, restaram 09 manuscritos (Figura 1).

Figura 1 - Fluxograma do processo de seleção dos artigos pesquisados.

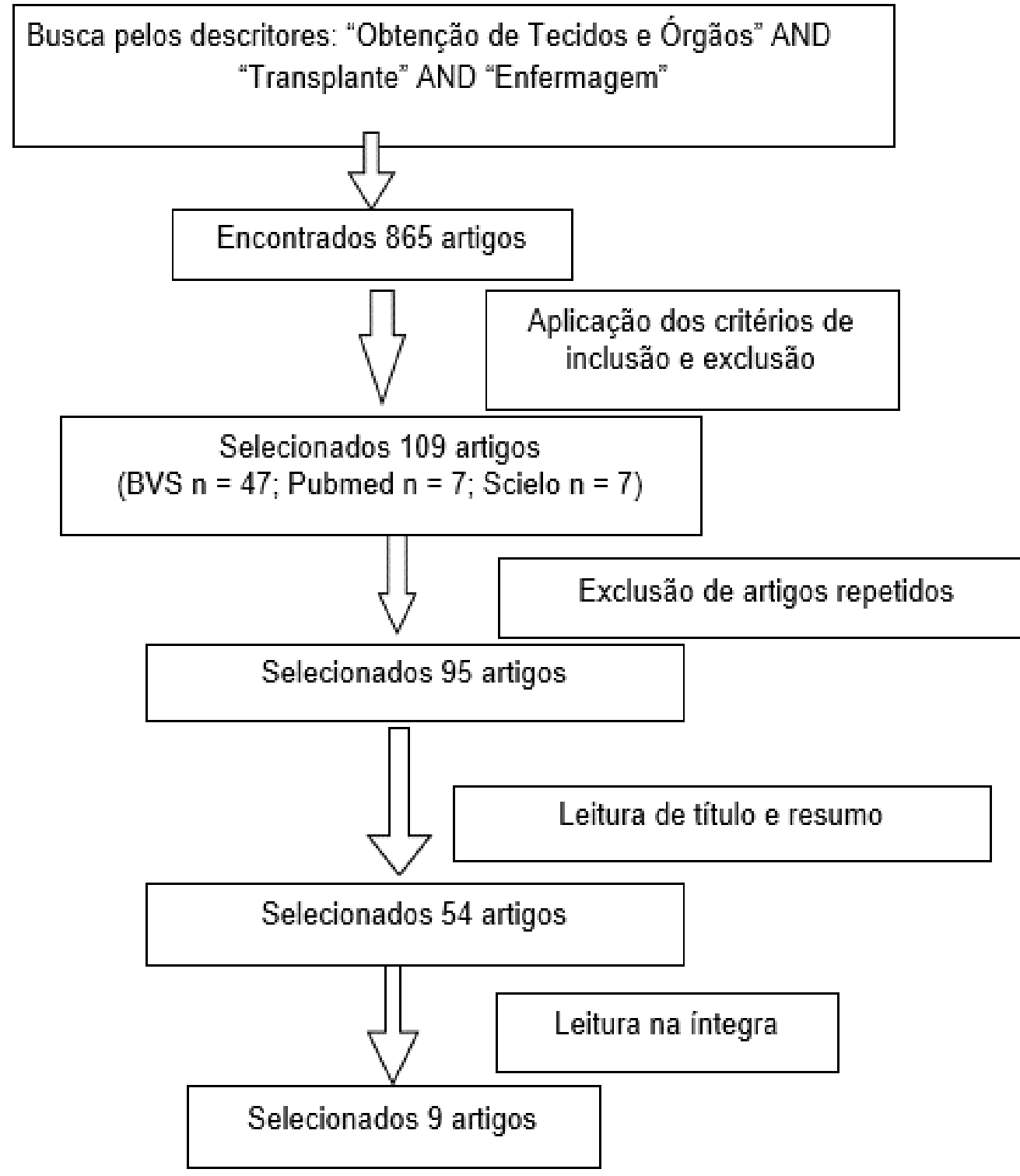

Fonte: Magalhães JB, et al., 2020.

Os 9 artigos selecionados foram expostos, analisados e organizados em um panorama organizacional das principais características apresentadas. 
Quadro 1 - Panorama organizacional das principais características dos artigos, procedimentos de coleta e análise e dos principais achados.

\begin{tabular}{|c|c|c|c|}
\hline Título da Publicação / Autores & $\begin{array}{l}\text { Local do } \\
\text { estudo }\end{array}$ & $\begin{array}{l}\text { Metodologia/ Procedimento } \\
\text { de coleta }\end{array}$ & Principais achados \\
\hline $\begin{array}{l}\text { Vivência de enfermeiros no processo } \\
\text { de doação de órgãos e tecidos para } \\
\quad \text { transplante } \\
\text { (MORAES EL, et al., 2014) }\end{array}$ & São Paulo & $\begin{array}{c}\text { Entrevistas individuais } \\
\text { guiadas, amostra por bola de } \\
\text { neve. }\end{array}$ & $\begin{array}{c}\text { O estudo trouxe a reflexão sobre a vivência dos enfermeiros no processo de } \\
\text { doação de órgãos e tecidos, a importância de oferecer subsídios assistenciais } \\
\text { aos profissionais de saúde, além de sinalizar estratégias para otimizar a } \\
\text { obtenção de órgãos e tecidos para transplantes. }\end{array}$ \\
\hline $\begin{array}{l}\text { Vivenciando a doação de órgãos: } \\
\text { sentimentos de familiares pós } \\
\text { consentimento. (FERNANDES, MEN, } \\
\text { et al., 2015) }\end{array}$ & São Paulo & $\begin{array}{l}\text { Questionário semiestruturado } \\
\text { contendo dados } \\
\text { sociodemográficos. }\end{array}$ & $\begin{array}{l}\text { O estudo identificou a necessidade de oferecer maior apoio sócio emocional } \\
\text { aos familiares de potenciais doadores frente à vivência do processo de } \\
\text { doação. A partir destes achados, outras práticas de atenção e gestão na saúde } \\
\text { poderão ser discutidas para impactar no fortalecimento dos vínculos familiares } \\
\text { pós-doação e nos índices de captação de órgãos. }\end{array}$ \\
\hline $\begin{array}{l}\text { Attitudes and knowledge e of nurses } \\
\text { on organ legacy and transplantation } \\
\text { (VLAISAVLJEVIC Z, et al., 2014) }\end{array}$ & Sérvia & $\begin{array}{l}\text { Estudo transversal realizado } \\
\text { com questionário sobre a } \\
\text { correlação entre a duração } \\
\text { do atendimento e o nível de } \\
\text { conhecimentos dos } \\
\text { profissionais de enfermagem. }\end{array}$ & $\begin{array}{l}\text { O estudo abordou sobre o conhecimento e as posturas diante do processo de } \\
\text { transplantes/doação de órgãos estão correlacionados ao nível de } \\
\text { conhecimento/escolaridade e aos anos de experiência profissional. A } \\
\text { disseminação do conhecimento do tema ajuda a dissipar preconceitos, } \\
\text { possibilita impacto significativo dos profissionais de enfermagem e nova } \\
\text { abordagem aos familiares de prováveis doadores e ao público em geral. }\end{array}$ \\
\hline $\begin{array}{l}\text { Conflitos éticos vivenciados por } \\
\text { enfermeiros no processo de doação } \\
\text { de órgãos } \\
\text { (ARAÚJO MN e MASSAROLLO } \\
\text { MCKB, 2014). }\end{array}$ & São Paulo & Estudo qualitativo & $\begin{array}{l}\text { O estudo apresenta conflitos éticos vivenciados pelos enfermeiros no processo } \\
\text { de doação de órgãos, foram eles: dificuldade do profissional em aceitar a ME; } \\
\text { não aceitação em desconectar o ventilador mecânico do paciente em ME, após } \\
\text { a comprovação de ME não ser doador de órgãos; desconhecimento para a } \\
\text { realização do protocolo de ME; falta de comprometimento profissional; descaso } \\
\text { no cuidado com o potencial doador; escassez de recursos humanos e } \\
\text { materiais; crenças religiosas e a falha na comunicação. }\end{array}$ \\
\hline $\begin{array}{l}\text { Os desafios enfrentados pela equipe } \\
\text { de enfermagem da comissão intra- } \\
\text { hospitalar de doação de órgãos e } \\
\text { tecidos para transplantes - } \\
\text { CIHDOTT } \\
\text { (JOÃO LF e SILVEIRA DC, 2015) }\end{array}$ & $\begin{array}{l}\text { Santa } \\
\text { Catarina }\end{array}$ & $\begin{array}{l}\text { Pesquisa qualitativa, } \\
\text { descritiva, exploratória com } \\
\text { entrevistas estruturadas. }\end{array}$ & $\begin{array}{l}\text { O estudo verificou falhas na educação continuada dos profissionais de } \\
\text { enfermagem que atuam na área. Evidenciou que a educação permanente, tem } \\
\text { a finalidade, de levantar a percepção dos profissionais e da sociedade sobre o } \\
\text { tema, o que estimula a participação e a promoção para desenvolver ações } \\
\text { eficazes sobre transplantes. }\end{array}$ \\
\hline
\end{tabular}

$\overline{\text { REAS/EJCH | Vol.12(10) | e4195 | DOI: https://doi.org/10.25248/reas.e4195.2020 Página } \mathbf{5} \text { de } \mathbf{1 0}}$ 


\section{Revista Eletrônica Acervo Saúde / Electronic Journal Collection Health | ISSN 2178-2091}

\begin{tabular}{|c|c|c|c|}
\hline Título da Publicação / Autores & $\begin{array}{l}\text { Local do } \\
\text { estudo }\end{array}$ & $\begin{array}{l}\text { Metodologia/ Procedimento } \\
\text { de coleta }\end{array}$ & Principais achados \\
\hline $\begin{array}{l}\text { Doação de órgãos e tecidos e } \\
\text { motivos de sua não efetivação } \\
\text { (BONETTI CE, et al., 2017) }\end{array}$ & Recife & $\begin{array}{l}\text { Pesquisa em prontuários de } \\
\text { pacientes caracterizados } \\
\text { como potenciais doadores }\end{array}$ & $\begin{array}{c}\text { O estudo contribuiu para conhecer alguns dos principais motivos da não } \\
\text { doação de órgãos e tecidos do paciente potencial doador, que contribuiu para } \\
\text { o desenvolvimento de estratégias que potencializam esse processo, } \\
\text { direcionados aos fatores modificáveis, e identificação dos motivos limitantes } \\
\text { para a efetivação. }\end{array}$ \\
\hline $\begin{array}{l}\text { Doar ou não doar: a visão de } \\
\text { familiares frente à doação de órgãos } \\
\text { (ROSSATO GC, et al., 2017) }\end{array}$ & $\begin{array}{l}\text { Rio Grande } \\
\text { do Sul }\end{array}$ & $\begin{array}{l}\text { Entrevista semiestruturada } \\
\text { gravada em áudio }\end{array}$ & $\begin{array}{c}\text { O estudo destacou a necessidade de estudos relacionados ao processo } \\
\text { vivenciado pelas famílias e sobre a ME no processo da decisão, de forma, que } \\
\text { seja possível compreender com mais propriedade as situações vivenciadas por } \\
\text { seus membros durante esse processo. }\end{array}$ \\
\hline $\begin{array}{l}\text { Perfil e motivos de negativas de } \\
\text { familiares para doação de órgãos e } \\
\text { tecidos para transplante. } \\
\text { (ARANDA RS, et al., 2018) }\end{array}$ & Bahia & $\begin{array}{l}\text { Estudo quantitativo, } \\
\text { transversal, retrospectivo } \\
\text { com formulários de entrevista } \\
\text { familiar em prontuários. }\end{array}$ & $\begin{array}{c}\text { O estudo identificou que houve prevalência da negativa familiar e a } \\
\text { identificação dos principais motivos para a não doação. O planejamento e } \\
\text { desenvolvimento de intervenções pode estimular a doação de tecidos e } \\
\text { órgãos. }\end{array}$ \\
\hline $\begin{array}{l}\text { Potencial doador cadáver: causas da } \\
\text { não doação de órgãos } \\
\text { (CORREIA WLB, et al., 2018). }\end{array}$ & Ceará & $\begin{array}{l}\text { Estudo quantitativo e } \\
\text { retrospectivo com utilização } \\
\text { de fichas de notificação de } \\
\text { paciente em ME. }\end{array}$ & $\begin{array}{c}\text { O principal motivo da não concretização da doação foi a recusa familiar (com } \\
\text { relação a crenças, ao desejo do doador em vida, a abordagem da família pela } \\
\text { equipe e a falta de confiança na equipe). O estudo sugere o desenvolvimento } \\
\text { de pesquisas na temática para nortear as políticas públicas, melhora das } \\
\text { informações a respeito da doação de órgãos e propagação na sociedade } \\
\text { contribuindo discussões na população. }\end{array}$ \\
\hline
\end{tabular}

Fonte: Magalhães JB, et al., 2020. 
Os desafios para a captação de órgãos estão presentes nas desigualdades regionais em transplante e são identificadas em países desenvolvidos e subdesenvolvidos (MORRIS PJ e MONACO AP, 2003). Para o Brasil segundo o Tribunal de Contas (2009), o cenário de acesso aos transplantes é desigual entre a população residente nos diversos Estados da Federação, com vantagem para os estados do Sul e do Sudeste. A Associação Brasileira de Transplante de Órgãos (ABTO) (2018), disponibiliza dados que mostram, que a região Norte aumentou os esforços para atingir a meta estabelecida para o ano de 2018. O que pode justificar uma maior produção de artigos referentes a temática nestes Estados.

Há obstáculos na obtenção de órgãos para transplantes, são eles: falha para identificar de um potencial doador, notificar e confirmar a situação de ME, por desconhecimento, desinteresse e sobrecarga de trabalho dos profissionais de saúde (MORAES EL, et al., 2014). Esses obstáculos geram ocupação prolongada nos leitos, principalmente em Unidades de Terapia Intensiva (UTI), aumento do sofrimento familiar e a perda de órgãos e tecidos para o transplante (DELL AGNOLO CM, et al., 2012).

Dessa forma, para a equipe de enfermagem, os obstáculos do processo de doação começam na identificação do possível doador, o que pode gerar uma reação em cadeia, que lentifica os protocolos e a confirmação do diagnóstico de ME, aumentando a demanda de pacientes na lista de espera. Outros obstáculos no processo de doação envolvem fatores como a escassez de recursos humanos e materiais, a manutenção da viabilidade dos órgãos para transplante e a liberação do corpo doador para o sepultamento (MORAES EL, et al., 2014).

A eficácia na comunicação entre a equipe desempenha uma função imprescindível no processo de doação, pois possibilita esclarecer as dúvidas dos familiares que são necessárias para a tomada de decisão sobre a doação e o transplante de órgãos (SIMINOFF LA, et al., 2009). Percebe-se que a enfermeira deve exercer uma função importante durante esse processo, que abrange desde a manutenção do potencial doador à projeções de ações que possibilitam a mudança de paradigmas dos profissionais de saúde, além da humanização da assistência aos familiares do doador falecido (MORAES EL, et al., 2014).

Dessa forma, o bom funcionamento das CIHDOTTs é importante para o aumento do número de doadores efetivos (SILVA OC, et al., 2011), uma vez que essas comissões, contribuem para a melhora nos processos envolvidos da doação, o que garante maior qualidade e quantidade dos órgãos fornecidos ao sistema público de transplante do País (ARCANJO RA, et al., 2013). Com o trabalho das CIHDOTTs há um aumento significativo no número de notificações de $\mathrm{ME}$ e do número de doadores efetivos quando se tem a presença da enfermeira especialista, além da redução das listas de espera para transplantes por meio da possibilidade da equidade, que é um dos pilares norteadores do SUS e deve ser respeitado de forma equânime (SILVA VS, et al., 2016).

Para que os resultados sejam crescentes em números de notificação de ME e de doadores efetivos, são necessárias intervenções educacionais e estruturais de profissionais especializados, a exemplos: formação do pessoal hospitalar capacitado para identificação do quadro de ME; introdução de registros institucionais específicos para gerir o processo de doação e implementação de prescrições médicas padronizadas baseados na evidência da manutenção do potencial doador (SILVA VS, et al., 2016).

Os potenciais doadores geralmente são captados em UTI, já que os mesmos requerem cuidados específicos e intensivos em virtude das várias alterações fisiológicas e principalmente hemodinâmicas (RODRIGUES SLL, et al., 2016). Segundo a Resolução do CFM no 2.173/17, para que se possa diagnosticar a ME, é necessário realizar exames clínicos e complementares durantes intervalos de tempo variáveis, próprios para cada faixa etária. Assim, os dados obtidos durante o protocolo de ME devem ser registrados no Termo de Declaração de Morte Encefálica, onde se deve constar o registro dos dois exames clínicos, realizados por médicos diferentes devidamente capacitados (CFM, 2017). Esses profissionais não podem estar vinculados com a equipe de captação e transplante de órgãos e tecidos (MORATO EG, 2009).

Em adultos, os intervalos entre as duas avaliações do protocolo ocorrem na diferença de 6 horas (SILVA VS, et al., 2016). Assim, quando se abre o protocolo, ocorre a entrevista familiar; este é um momento delicado, pois a gravidade e iminência da morte são situações traumáticas, devido a não aceitação da perda, o que 
resulta em estresse e tristeza para os familiares (MOREIRA CV e FERRAZ BER, 2009). Desse modo, entre as variadas causas que levam a não efetivação da doação são fatores modificáveis, dentre eles, é visto, principalmente a recusa familiar (BONETTI CE, et al., 2017).

João LF e Silveira DC (2015) apresentam que a atuação da equipe está relacionada com a busca ativa de doação, captação e divulgação sobre o assunto. As principais condutas citadas, quanto aos questionamentos da conduta da equipe, são: a conscientização da doação, a identificação do paciente doador e acolhimento adequado para os familiares. As principais ações da equipe, frente às dificuldades vivenciadas pelos familiares, devem ser baseadas em boa orientação e atendimento de qualidade. Os desafios enfrentados pela enfermeira incluem: falta de treinamento e de conhecimento do assunto pela sociedade que ainda não vêm à doação como algo positivo. Aponta-se, então, para a necessidade da educação continuada, a fim de desenvolver melhor desenvoltura na relação, diálogo e aproximação com a família no momento da doação.

Observa-se nos artigos encontrados que a recusa familiar é uma das principais causas para a não captação de órgãos para transplante, em seguida vem às contraindicações médicas e/ou perda da janela do tempo de manutenção do órgão para o transplante, a exemplo, a parada cardíaca. Os aspectos que mais são prevalentes nas decisões familiares são: religião/crenças, desconhecimento do desejo do familiar, manutenção da integridade corporal, dúvidas geradas pela equipe médica e a abordagem inadequada dos profissionais de captação de órgãos para transplante (NORONHA MGO, et al., 2012).

Porém, acredita-se que o principal motivo da recusa familiar, ainda seja a falta de conhecimento acerca do assunto. Ou seja, a não compreensão do diagnóstico de ME é apontada como a principal causa dessa recusa, pois há dificuldades de compreender que um corpo que ainda possui batimentos cardíacos, respiração e, por vezes, até temperatura corpórea possa estar morto (PESSOA JLE, et al., 2013). Outro fator atribuído a recusa familiar é o desconhecimento da família sobre a vontade do paciente (BONETTI CE, et al., 2017).

Também é observado que estabelecer e manter uma boa relação entre profissionais de saúde e familiares, pode fortalecer o vínculo de confiança entre eles. Com isso as informações passadas pela equipe são mais aceitas (CORREIA WLB, et al., 2018). Dessa forma, identifica-se, que dar suporte os familiares, fornecer informações sobre todo o processo, acolher e estar atento as emoções são essenciais para encorajar a doação, deve-se atentar para uma assistência e uma escuta qualificada a família e ao doador (CORREIA WLB, et al., 2018).

Em relação a não doação, cabe destacar que, tal decisão pela família, não quer dizer que foi de maneira simples e fácil, e sim, que a família já se encontra tão saturada de emoções ocasionadas pela experiência de acompanhar seu parente em ME, que prefere se manter em um contexto que se sinta segura, sem novas notícias ou eventos desconhecidos (ROSSATO GC, et al., 2017). A família que opta pela doação, associa ao ato vários significados, entre eles: conforto, satisfação, honra, entre outras sensações boas, porque significa fazer o bem ou poder contribuir a mudança de vida de outras pessoas que esperam por um transplante por meio da doação de órgãos (ROSSATO GC, et al., 2017).

Araújo MN e Massarollo MCKB (2014) revelam que a situação que repercute no momento da entrevista familiar é a dificuldade em aceitar a ME. A não aceitação pode se estender a equipe multiprofissional, ao desconectar o ventilador mecânico do paciente em ME não doador de órgãos. Este é um dos maiores conflitos vivenciados pelos profissionais, que mesmo sob posse do conhecimento da legislação e do protocolo institucional que respaldam essa ação, observa-se a dificuldade e insegurança em desconectar o aparelho que mantém aquele indivíduo artificialmente "vivo". Associado a isso, evidencia-se o impasse dos profissionais em esclarecer a família sobre a situação, já que sentimento dos familiares é de esperança e fé e que manter o aparelho conectado poderá trazer seu ente a vida.

A partir da análise realizada nas publicações observa-se, desafios encontrados pela enfermagem durante o processo de doação para transplante de órgãos, destes a negação/recusa familiar apareceu como um indicador para as taxas na captação de órgãos e tecidos. Assim, há necessidade de se oferecer maior apoio socioemocional aos familiares de potenciais doadores frente à vivência do processo de doação. A partir destes 
achados, outras práticas de atenção e gestão na saúde poderão ser discutidas para impactar no fortalecimento dos vínculos familiares pós-doação e nos índices de captação de órgãos (FERNANDES MEN, et al., 2015).

Aos profissionais da equipe de enfermagem é necessário suscitar reflexões, sensibilizando-os para compreender a situação vivenciada pelos familiares, proporcionando que estas se sintam acolhidas e respeitadas pelo serviço (ROSSATO GC, et al., 2017). Para a tomada de decisão frente a conflitos éticos a equipe de enfermagem deve utilizar o diálogo a fim de fortalecer a comunicação e o trabalho em equipe, assim se assume uma posição frente ao conflito. Por vezes, as razões que mais o motivam essa posição são a legislação e o princípio da beneficência.

\section{CONSIDERAÇÕES FINAIS}

Esta pesquisa identificou os principais desafios que a equipe de enfermagem enfrenta no processo de doação para transplante de órgãos, que são: as dificuldades na identificação e confirmação da morte encefálica e a negação/recusa familiar. Também foi possível compreender as situações que levam a essa recusa familiar. A partir do conhecimento dessas situações são apresentados elementos que podem nortear a atuação das equipes de captação de órgãos, a fim de sensibilizar a população para a importância da doação. A pesquisa sinaliza a fragilidade da equipe de enfermagem e as formas de ação diante da temática, pois muitos profissionais sabem como devem agir, mas o processo pode ser desgastante, pesaroso e o que repercute, muitas vezes, a não efetivação da doação. Como soluções aos desafios estão: priorizar as comissões intra-hospitalares, realizar uma avaliação clínica adequada e a comunicação adequada da equipe com a família e apoio socioemocional. Trata-se de uma temática relevante nas perspectivas social e científica, contudo, requer melhor conscientização da população, por meio de propagandas e campanhas que valorizem e demonstram a importância da doação de órgãos para transplante, assim com a implementação e/ou criação de políticas públicas para que esse processo seja efetivado de forma a beneficiar um número maior de pessoas que aguardam na fila de espera por um órgão ou tecido.

\section{REFERÊNCIAS}

1. ABTO. Associação Brasileira de transplante de Órgãos. Dados numéricos da doação de órgãos e transplantes realizados por estado e instituição no período: janeiro / março - 2018. Registro Brasileiro de Transplante, 2018.

2. ABTO. Associação Brasileira de transplante de Órgãos. Registro Brasileiro de Transplantes, Estatística de Transplantes ano XXV (4), 2019.

3. ABTO. Associação Brasileira de transplante de Órgãos. Ministério da Saúde. Conselho Federal de Medicina, 2020.

4. ARAÚJO MN, MASSAROLLO MCKB. Conflitos éticos vivenciados por enfermeiros no processo de doação de órgãos. Acta Paulista de Enfermagem, 2014; 27(3):215-220.

5. ARANDA RS, et al. Perfil e motivos de negativas de familiares para doação de órgãos e tecidos para transplante. Revista Baiana de Enfermagem, 2018; 32: e27560.

6. ARCANJO RA, et al. Reflexões sobre a comissão intra-hospitalar de doação de órgãos e tecidos para transplantes. Revista Bioética, 2013; 21(1):119-125.

7. BACCHELLA T, OLIVEIRA RA. Bioética dos Transplantes In: Segre, M. A Questão Ética e a Saúde Humana. São Paulo: Atheneu, 2006; 133p.

8. BONETTI CE, et al. Doação de órgãos e tecidos e motivos de sua não efetivação. Revista de Enfermagem UFPE online, 2017; 12(9):3533-3541.

9. BRASIL. Ministério da Saúde. Lei 9.434 , de 4 de fevereiro de 1997. Dispõe sobre a remoção de órgãos, tecidos e partes do corpo humano para fins de transplante e tratamento e dá outras providências, 1997.

10. BRASIL. Ministério da Saúde. Lei 10.211, de 23 de março de 2001. Altera os dispositivos da Lei no 9.434, de 4 de fevereiro de 1997, que "dispõe sobre a remoção de órgãos, tecidos e partes do corpo humano para fins de transplante e tratamento", 2001.

11. BRASIL. Ministério da Saúde. Resolução no 2.173/17. Conselho Federal de Medicina atualiza resolução com critérios de diagnóstico da morte encefálica, 2017.

12. BRASIL. Decreto no 9.175 , de 18 de outubro de 2017. Regulamenta a Lei $n^{\circ} \mathbf{9 . 4 3 4}$, de 4 de fevereiro de 1997 , para tratar da disposição de órgãos, tecidos, células e partes do corpo humano para fins de transplante e tratamento, 2017.

13. BRASIL. Ministério da Saúde. Doação de Órgãos: transplantes, lista de espera e como ser doador, 2020.

14. BRASIL. Conselho Federal de Enfermagem. Resolução no $611 / 2019$. Atualiza a normatização referente à atuação da Equipe de Enfermagem no processo de doação de órgãos e tecidos para transplante, e dá outras providências, 2019.

15. CORREIA WLB, et al. Potencial doador cadáver: Causas da não doação de órgãos. Enfermagem em Foco, 2018; $9(3): 30-34$. 
16. CONSELHO FEDERAL DE MEDICINA. Resolução n. 1346, de 1991. Estabelece critérios para a caracterização da parada total e irreversível das funções encefálicas em pessoas com mais de dois anos de idade. Diário Oficial da União; Poder Executivo, Brasília, 1991.

17. CONSELHO FEDERAL DE MEDICINA. Resolução n. ${ }^{-2}$ 2.173, de 23 de novembro de 2017. Tratar da disposição de órgãos, tecidos, células e partes do corpo humano para fins de transplante e tratamento. Diário Oficial da União; Poder Executivo, Brasília, 2017.

18. DALBEM GG, CAREGNATO RC. Doação de órgãos e tecidos para transplante: recusa das Famílias. Texto e Contexto Enfermagem, 2010; 4(19):728-735.

19. DELL AGNOL OCM, et al. Causes oforgandonation failure in Brazil. Transplantation Proceedings, 2012; 44:2280-2282.

20. FERNANDES MEN, et al. Vivenciando a doação de órgãos: sentimentos de familiares pos consentimento. Revista Latino-Americana de Enfermagem, 2015; 23(5):895-901.

21. FREIRE ILS, et al. Morte encefálica e cuidados na manutenção do potencial doador de órgãos e tecidos para transplante. Revista Eletrônica de Enfermagem, 2012; 14(4):903-912

22. JOÃO LF, SILVEIRADC. Os desafios enfrentados pela equipe de enfermagem da comissão intra-hospitalar de doação de órgãos e tecidos para transplantes - CIHDOTT. Arquivo Catarinense de Medicina, 2015; 44(4):82-86.

23. MATTIA AL, et al. Análise das dificuldades no processo de doação de órgãos: uma revisão integrativa da literatura. Revista Bioethikos, 2010; 4(1):66-74.

24. MENDES KDS, et al. Revisão Integrativa: método de pesquisa para incorporação de evidências na saúde e na Enfermagem. Texto Contexto Enfermagem, 2008; 17(4):758-764.

25. MORAES EL, et al. Vivência de enfermeiros no processo de doação de órgãos e tecidos para transplante. Revista Latino-Americana de Enfermagem, 2014; 22(2):226-233.

26. MORATO EG. Morte encefálica: conceitos essenciais, diagnóstico e atualização. Revista Médica Minas Gerais, 2009; 19(3):227-236.

27. MOREIRA CV, FERRAZ BER. A receptividade da notícia da morte encefálica nos familiares de doadores de órgãos e tecidos para transplante. Enfermería Global, 2009; 16:1-82.

28. MORRIS PJ, MONACO, AP. Geographic disparities in access to organ transplant Introduction. Transplantation, 2003; 76(9):1380-1383.

29. NORONHA MGO, et al. Estudo do perfil dos doadores elegíveis de órgãos e tecidos e motivos da não doação no Hospital Santa Isabel em Blumenau, SC. Revista AMRIG, 2012; 56(3):199-203.

30. PESSOA JLE, et al. Avaliação das causas de recusa familiar a doação de órgãos e tecidos. Acta paulista de enfermagem, 2013; 26(4):323-330.

31. RODRIGUES SLL, et al. Profile of effective donors from organ and tissue procurement services. Rev. bras. ter. intensiva [online], 2014; 26(1):21-27.

32. ROSSATO GC, et. al. Doar ou não doar: a visão de familiares frente à doação de órgãos. Revista Mineira de Enfermagem, 2017; $21: e-1056$.

33. SILVA OC, et al. Donation of organs for transplants in brazil: what is missing? What can be done?. Arquivo Brasileiro de Cirurgia Digestiva, 2011; 24(2):93-4.

34. SILVA VS, et al.. Projeto de coordenação intra-hospitalar para doação de órgãos e tecidos: responsabilidade social e resultados promissores. Revista Latino-Americana de Enfermagem, 2016; $24: \mathrm{e} 2773$.

35. SIMINOFF LA, et al. Communicating effectively about donation: an educational intervention to increase consent to donation. ProgramTransplant, 2009; 19(1):35-43.

36. SOARES LSS, et al. Transplantes de órgãos sólidos no Brasil: estudo descritivo sobre desigualdades na distribuição e acesso no território brasileiro, 2001-2017. Epidemiol. Serv. Saúde, 2020; 29 (1):e2018512.

37. TRIBUNAL DE CONTAS DA UNIÃO. Relatório de avaliação de programa. Programa doação, captação e transplante de órgãos e tecidos, 2008.

38. VLAISAVLJEVIĆ Z, et al. Attitude sand Knowledge of Nurses on Organ Legacy and Transplantation. Serbian Archives of Medicine, 2014; 142(3-4):213-218.

39. WESTPHAL GA, et al. Diretrizes para manutenção de múltiplos órgãos no potencial doador adulto falecido. Parte II. Ventilação mecânica, controle endócrino metabólico e aspectos hematológicos e infecciosos. Revista Brasileira de Terapia intensiva, 2011; 23(3):269-282. 